\title{
Neuroprotective Activity of Methanolic extract of Terminala bellerica Fruit against Aluminium Chloride and Haloperidol Induced Amnesia in Mice
}

\author{
N V L Suvarchala Reddy V*, Ganga Raju M, Rahul Goud M, Shabnamkumari T \\ Department of Pharmacology, Gokaraju Rangaraju College of Pharmacy, Nizampet Village, Bachupally, Hyderabad, Telangana, INDIA.
}

\begin{abstract}
Objectives: The data presented in the article is related to evaluation of Terminalia bellerica fruits methanol extract (METB) for the neurodegenerative disorders along with their antioxidant potential. Methods: Various phytoconstituents were identified with proximate phytochemical analysis of METB. Terminalia species are gallic acid and chebulaginic acid which are known to possess neuroprotective activity and are also known to contain various flavonoids and phenols as active constituents. The methanolic fruit extract of Terminalia bellerica was screened for its Neuroprotective Activity against Aluminium Chloride and Haloperidol Induced Amnesia in Mice. Results: In vitro AChEs assay, METB showed $\mathrm{IC}_{50} 34.5 \mu \mathrm{g} / \mathrm{ml}$ and also significantly reduced brain $\mathrm{AChE}$. In addition, it exhibited remarkable radical scavenging potential in reducing power assay (increasing absorbance) and lipid peroxidation assays (IC $\left.\mathrm{C}_{50} 39.25 \mathrm{\mu g} / \mathrm{ml}\right)$. In vivo neuroprotective activities were performed via the passive avoidance, plus maze tasks in aluminium chloride induced amnesia model and via rota rod apparatus, standard bar test in haloperidol induced catalepsy model. METB showed significant $(p<0.01, p<0.05)$ improvement in cognitive impairment in aluminium
\end{abstract}

chloride induced amnesia animal models and moderate inhibitory activities. The results demonstrate that the anti-amnesic effect of METB may be mediated via antioxidant capabilities, as well as inhibition of AChEs and due to the presence of various terpenoids, flavonoids and phenols as active constituents. Conclusion: Furthermore Terminalia bellerica ayurvedic plant can be used in various neurological disorders.

Key words: Terminala bellerica, Anti-amnesia, Neuroprotection, Aluminium chloride, Haloperidol, Acetylcholinesterase.

Correspondence

Dr. N V L Suvarchala Reddy V,

Department of Pharmacology, Gokaraju Rangaraju College of Pharmacy, Bachupally, Hyderabad 500090, Telangana, INDIA.

Phone: +919000811806

Email: suvarchalakiran@gmail.com

DOI: $10.5530 /$ jyp.2020.12s.53

\section{INTRODUCTION}

Alzheimer's disease $(\mathrm{AD})$ is an advanced neurodegenerative ailment connected with the damage of reminiscence, linguistic and other perceptive injuries in the elderly populace. The cause of $\mathrm{AD}$ is multifactorial and entails many issues, including pate shock, heredities, oxidative stress, swelling, proteasomal dysfunction and ecological types such as aluminium (Al) toxicity. $\mathrm{Al}$ is a profusely present neurotoxin, enormously exposed to humans and revealed to accrue in $\mathrm{AD}$ susceptible brain regions such as cortex and hippocampus. ${ }^{1,2}$ Additionally, Al distracts amyloid precursorprotein (APP) digestion from its non-amyloidogenic path to the amyloidogenic pathway, thereby favours the formation of $\beta$-amyloid oligomers, fibrils and plaques. ${ }^{3}$

Haloperidol-induced catalepsy arises owing to the obstruction of dopamine $\left(\mathrm{D}_{2}\right)$ receptors and abridged dopaminergic transmission. ${ }^{3}$ The improved stimulus of the integrated central cholinergic system has also been concerned in haloperidol-induced catalepsy as it has been stated to be strengthened and antagonized by pilocarpine andatropine, respectively. ${ }^{4}$ Evidence also proposes that the central serotonergic system modifies nigrostriatal dopaminergic transmission with 5-HT3 antagonists stated to improve narcoleptic-induced catalepsy. ${ }^{5}$ The phenomenon of cataleptic immovability brought in rodents by typical narcoleptics (e.g., haloperidol) is a vigorous behavioural model to study nigrostriatal function and its modulation by cholinergic, serotonergic and other neurotransmitter systems.

Terminalia belerica. Roxb (TB) is grown widely throughout the Indian subcontinent, Sri Lanka and SE Asia. In the Traditional system of medicine
(TCM) like Ayurveda, Siddha and Unani, medicinal uses have been described as it works in the disease of every system. Glycoside, Tannins, Gallic acid, Ellagic acid, Ethylgalate, Gallyl glucose, Chebulanic acid are mainly believed to be responsible for its extensive therapeutic actions. It is used as an antioxidant, antimicrobial, anti-diarrheal, anticancer, antidiabetic, antihypertensive and hepatoprotective agent. The present article attempts to study the anti-amnesic activity of Terminalia belerica fruit. ${ }^{6}$

\section{MATERIALS AND METHODS}

\section{Plant collection and extraction}

Fruits of Terminalia bellerica were collected from a local market during December 2016. Crude plant material was identified and authenticated by Botanist (Voucher specimen no., TBR-6) from Government Degree College Kukatpally, Hyderabad. Fruits were dried in the shade; coarsely powdered and powdered material was used for the extraction process.

\section{Chemicals and reagents}

Triton X-100 used was a product of SRL Chemicals, Sisco Research Laboratories Pvt Ltd., Maharashtra, India. Simvastatin drug used was a product of Sun Pharmaceuticals India LTD., Mumbai, India. Biochemical kits and all other chemicals were of analytical grade.

\section{Preparation of extract}

The powdered crude material of Terminalia bellerica fruits was extracted with methanol by Soxhlation and crude extract obtained was evaporated 
to a solid mass and stored in desiccators to remove remaining moisture, if present.

\section{Animals}

Wistar albino mice 20 to $25 \mathrm{~g}$ were procured from Albino research lab, Hyderabad. Data protocol of the present study was carried out in CPCSEA approved by IAEC (Reg. No. 1175/PO/ERe/S/08/CPCSEA) animal house of Gokaraju Rangaraju College of Pharmacy, Bachupally and Hyderabad, India.

\section{Acute toxicity studies}

An acute toxicity study up and down procedure (OECD guideline-425) was carried out for methanolic extract of Terminalia bellerica on female Wistar rats. ${ }^{?}$

\section{In vitro model}

Evaluation of AChE inhibitory activity using AChE inhibitory assay

The acetyl cholinesterase inhibitory activity was evaluated for METB by the Ellman's assay. ${ }^{8}$

\section{In vivo models}

The in vivo evaluation of neuroprotective activity of the methanolic extract of Terminalia bellerica fruits was carried out in the following models.

\section{Aluminium chloride induced chronic amnesic model}

Vigorous Swiss albino mice of both sex weigh up to 20-25 g were selected for present study and these animals were divided into 5 groups (6 in each group). Group-I control mice, Group-II disease control received $\mathrm{AlCl}_{3}\left(100 \mathrm{mg} / \mathrm{kg}\right.$, p.o) for $1-42$ days, Group-III $\mathrm{AlCl}_{3}(100 \mathrm{mg} / \mathrm{kg}$, p.o $)$ for 1-41 days + METB (200 mg/kg, p.o) for 21-41 day, Group-IV $\mathrm{AlCl}_{3}$ (100mg/kg, p.o) for 1-41 days + METB (400 mg/kg, p.o) for 21-41 days, Group-V $\mathrm{AlCl}_{3}(100 \mathrm{mg} / \mathrm{kg}$, p.o) for 41 days + Donepezil (1mg/kg, p.o) for 21-41 days.

At the predetermined time intervals, i.e., on $20^{\text {th }}, 21^{\text {st }}$ and $42^{\text {nd }}$ day the behavioural parameters like transfer latency by elevated plus maze and time taken to climb pole by using Cook's pole climbing apparatus were evaluated by using exteroceptive screening models. ${ }^{9}$

\section{Haloperidol induced catalepsy model}

Vigorous Swiss albino mice of both sexes weigh up to 20-25 g were selected for the present study and these animals were divided into 5 groups (6 in each group). Group-I control mice, Group-II disease control received Haloperidol (1 mg/kg, i.p.), Group-III METB (200 mg/kg, p.o.) for 21 days + Haloperidol (1mg/kg, i.p.), Group-IV METB (400 mg/kg, p.o.) for 21 days + Haloperidol (1 mg/kg, i.p.), Group-V L-DOPA+ Carbidopa $(100+25 \mathrm{mg} / \mathrm{kg}$, p.o $)$ for 21 days + Haloperidol ( $1 \mathrm{mg} / \mathrm{kg}$, i.p. $)$. A cataleptic behaviour was measured with a rota rod apparatus (rod rotating at the speed of $20 \mathrm{rpm}$ for $5 \mathrm{~min}$.) and a standard bar test method. ${ }^{10}$

\section{Statistical analysis}

The results were expressed as mean \pm SEM. The effects were exposed to the statistical investigation by using one way ANOVA followed by Dunnett's test $p<0.05, p<0.01$ was considered statistically significant.

\section{RESULTS AND DISCUSSION}

Methanolic extract of Terminalia bellerica fruit was explored for its neuro protective and anti-inflammatory activities using suitable animal models and its antioxidant activity was also screened by in vitro antioxidant assays. All the results obtained in the study were included below.
Table 1: AChE inhibition of methanolic fruit extract of Terminalia bellerica.

\begin{tabular}{ccc}
\hline S. No. & Test compounds & IC $_{50}$ value \\
\hline 1 & METB & 34.5 \\
2 & Donepezil & 31.5 \\
\hline
\end{tabular}

Histopathology study of hippocampus region of mice brain in aluminium chloride induced chronic amnesic model

On $42^{\text {nd }}$ day, mice were sacrificed to separate brains, which were fixed in $10 \%$ formalin for $24 \mathrm{~h}$ and used for histopathological studies. The pathological changes were viewed under light microscope after staining with haematoxylin and eosin. The data of histopathological studies were shown in Figure 1.

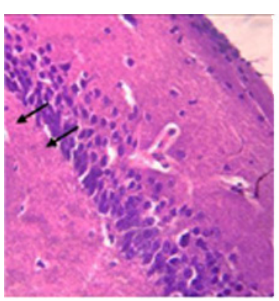

A

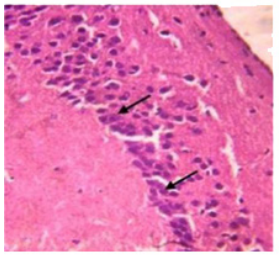

D

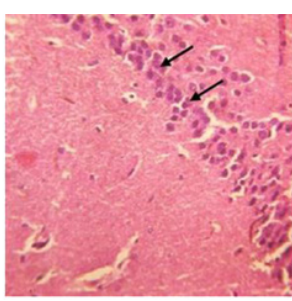

B

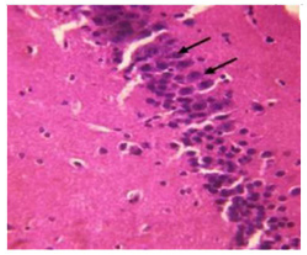

E

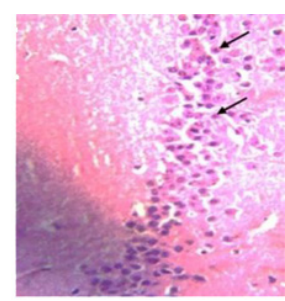

C
Figure 1: Histopathology of hippocampus region of mice brain in aluminium chloride induced chronic amnesic model.

A. Control animal showed five to six layers of compactly arranged small pyramidal cells with vesicular nuclei in CA1 region of Hippocampus. B. Two to three layers of shrinked pyramidal cells of CA1 region of hippocampus with irregular arrangement and most of the nucleus appears pale in colour was observed Group II (disease control received $\mathrm{AlCl}_{3}(100 \mathrm{mg} / \mathrm{kg}, p . o)$. C. Increased layer of pyramidal cells with dark prominent nucleus appears in CA1 region of hippocampus. Arrangement of neurons is still improper in Group III $\left(\mathrm{AlCl}_{3}(100 \mathrm{mg} / \mathrm{kg}\right.$, p.o) for 1-41 days + METB $(200 \mathrm{mg} / \mathrm{kg}$, p.o for 21-41 day) mice brain. $\mathbf{D}$. Four to five layers of pyramidal cells with regular arrangement at deeper layer was observed in CA1 region of hippocampus in Group IV $\left(\mathrm{AlCl}_{3}(100 \mathrm{mg} / \mathrm{kg}, p .0)\right.$ for $1-41$ days + METB $(400 \mathrm{mg} / \mathrm{kg}, p .0)$ for 21-41 day) mice brain. E. Five to six layers of regularly arranged pyramidal cells with prominent nucleus appearing in CA1 region of hippocampus in Group V $\left(\mathrm{AlCl}_{3}(100 \mathrm{mg} / \mathrm{kg}\right.$, p.o) for 41 days + Donepezil $(1 \mathrm{mg} / \mathrm{kg}, p .0)$ for 21-41 days) mice brain.

\section{Preliminary Phytochemical analysis}

The preliminary phytochemical investigation of methanolic extract of Terminalia bellerica fruits showed the presence of phenolic compounds, alkaloids, flavonoids, steroids, terpenoids, glycosides, carbohydrates.

\section{Acute toxicity studies}

Methanolic extract of Terminalia bellerica fruits was tested on albino Swiss mice up to a dose of $2000 \mathrm{mg} / \mathrm{kg}$ bd. wt. The animal did not exhibit any signs of toxicity or mortality up to $2000 \mathrm{mg} / \mathrm{kg}$ bd. wt. various morphological and behavioural characters were observed during the 
Table 3: Effect of METB on Transfer latency time using elevated plus maze.

\begin{tabular}{ccccc}
\hline \multirow{2}{*}{ Groups } & \multirow{2}{*}{ Treatment } & \multicolumn{3}{c}{ Transfer latency (secs) } \\
\cline { 3 - 5 } & & $\mathbf{0}^{\text {th }}$ day & $\mathbf{2 1}^{\text {st }}$ day & $\mathbf{4 2}^{\text {nd }}$ day \\
\hline I & Normal Control & $16.83 \pm 0.83$ & $17.83 \pm 0.60$ & $16.17 \pm 0.70$ \\
& Negative control & $15.83 \pm 0.91$ & $29.83 \pm 0.70^{* *, \mathrm{~A}}$ & $31.50 \pm 0.67^{* *, \mathrm{~A}}$ \\
II & $\left(\mathrm{AlCl}_{3} 100 \mathrm{mg} / \mathrm{kg}\right)$ & & & \\
III & METB $(200 \mathrm{mg} / \mathrm{kg})$ & $17.33 \pm 0.67$ & $27.50 \pm 0.43^{* *, \mathrm{~A}}$ & $24.50 \pm 0.62^{* *, \mathrm{~A}, \mathrm{a}}$ \\
IV & METB $(400 \mathrm{mg} / \mathrm{kg})$ & $18.17 \pm 0.60$ & $25.67 \pm 0.61^{* *, \mathrm{~A}, \mathrm{a}}$ & $23.33 \pm 0.49^{* *, \mathrm{~A}, \mathrm{a}}$ \\
V & Donepezil $(1 \mathrm{mg} / \mathrm{kg})$ & $16.83 \pm 0.83$ & $21.83 \pm 0.65^{* *, \mathrm{a}}$ & $20.33 \pm 0.61^{* *, \mathrm{~A}}$ \\
\hline
\end{tabular}

Values were expressed as mean \pm SEM $(n=6)$. Statistical analysis was performed by using ANOVA followed by Dunnett's t-test by comparing with control, negative control and standard. Significant values are expressed as control group $\left({ }^{* *} p<0.01\right.$, $\left.{ }^{*} p<0.05\right)$, negative control $(\mathrm{a}=p<0.01, \mathrm{~b}=p<0.05)$ and standard $(\mathrm{A}=p<0.01$, $p<0.05)$.

\section{Aluminium chloride induced amnesia model}

Table 2: Effect of METB on passive avoidance time using cooks pole climbing apparatus.

\begin{tabular}{ccccc}
\hline \multirow{2}{*}{ Groups } & \multirow{2}{*}{ Treatment } & \multicolumn{3}{c}{ Time taken to climb pole (secs) } \\
\cline { 3 - 5 } & & $\mathbf{0}^{\text {th }}$ day & $\mathbf{2 1}^{\text {st }}$ day & $\mathbf{4 2}^{\text {nd }}$ day \\
\hline I & Normal Control & $20.83 \pm 0.91$ & $21.83 \pm 0.70$ & $19.5 \pm 0.43$ \\
& Negative control & $21.83 \pm 0.75$ & $30.33 \pm 0.49^{* *}$, & $32.5 \pm 0.62^{* *, A}$ \\
II & $\left(\mathrm{AlCl}_{3} 100 \mathrm{mg} / \mathrm{kg}\right)$ & & & \\
III & METB $(200 \mathrm{mg} / \mathrm{kg})$ & $21.5 \pm 0.67$ & $29.33 \pm 0.67^{* *, \mathrm{~A}}$ & $27 \pm 0.68^{* *, \mathrm{~A}, \mathrm{a}}$ \\
IV & METB $(400 \mathrm{mg} / \mathrm{kg})$ & $19.33 \pm 0.76$ & $27.83 \pm 0.75^{* *, \mathrm{~B}, \mathrm{~b}}$ & $25.67 \pm 0.76^{* *, \mathrm{~B}, \mathrm{a}}$ \\
V & Donepezil $(1 \mathrm{mg} / \mathrm{kg})$ & $20.17 \pm 0.79$ & $25.5 \pm 0.43^{* *, \mathrm{~b}}$ & $23.33 \pm 0.61^{* *, \mathrm{a}}$ \\
\hline
\end{tabular}

Values were expressed as mean \pm SEM $(n=6)$. Statistical analysis was performed by using ANOVA followed by Dunnet's $t$-test by comparing with control, negative control and standard. Significant values are expressed as control group $\left({ }^{* *} p<0.01\right)$, negative control $(\mathrm{a}=p<0.01, \mathrm{~b}=p<0.05)$ and standard $(\mathrm{A}=p<0.01, \mathrm{~B} p<0.05)$.

\section{Haloperidol induced catalepsy model}

\section{Table 4: Effect of METB on muscle rigidity (Rota rod test).}

\begin{tabular}{|c|c|c|c|c|c|}
\hline \multirow{2}{*}{ Groups } & \multirow[t]{2}{*}{ Treatment } & \multicolumn{4}{|c|}{ Fall off time (sec) } \\
\hline & & Day 0 & Day 7 & Day 14 & Day 21 \\
\hline I & Normal Control & $102.33 \pm 0.80$ & $100.17 \pm 0.91$ & $98.83 \pm 0.65$ & $102.5 \pm 0.85$ \\
\hline II & Negative control (Haloperidol 1 mg/kg) & $104.83 \pm 0.95$ & $79.17 \pm 0.70^{* *}, \mathrm{~A}$ & $59.5 \pm 0.85^{* *, A}$ & $48.83 \pm 0.87^{* *}, \mathrm{~A}$ \\
\hline III & METB (200 mg/kg) & $101.50 \pm 0.56$ & $82.67 \pm 0.84^{* *, A, b}$ & $86.17 \pm 0.75^{* *, A, a}$ & $89.17 \pm 0.70^{* *, A, a}$ \\
\hline IV & METB (400 mg/kg) & $102.17 \pm 0.79$ & $84.17 \pm 0.91^{* *, \mathrm{~B}, \mathrm{a}}$ & $90.17 \pm 0.87^{* *, A, a}$ & $95.67 \pm 0.71^{* *, B, a}$ \\
\hline $\mathrm{V}$ & L-DOPA+ Carbidopa $(100+25$ mg/kg, p.o $)$ & $103.67 \pm 0.92$ & $87.5 \pm 0.72^{* *, a}$ & $94.17 \pm 0.83^{* *, a}$ & $98.83 \pm 0.79^{*}, \mathrm{a}$ \\
\hline
\end{tabular}

Values were expressed as mean \pm SEM $(n=6)$. Statistical analysis was performed by using ANOVA followed by Dunnet's t-test by comparing with control, negative control and standard. Significant values are expressed as control group $\left({ }^{*} p<0.01,{ }^{*} p<0.05\right)$, negative control $(\mathrm{a}=p<0.01, \mathrm{~b}=p<0.05)$ and standard $(\mathrm{A}=p<0.01, p<0.05)$

Table 5: Effect of METB on cataleptic scores using standard bar test.

\begin{tabular}{|c|c|c|c|c|c|c|c|}
\hline \multirow{2}{*}{ Groups } & \multirow[t]{2}{*}{ Treatment } & \multicolumn{6}{|c|}{ Cataleptic scores (sec) } \\
\hline & & 30 Min & 60 Min & 90 Min & 120 Min & 180 Min & 240 Min \\
\hline I & Normal Control & $16.17 \pm 0.91$ & $17.83 \pm 0.7$ & $16.5 \pm 0.85$ & $17.17 \pm 0.91$ & $17.33 \pm 0.99$ & $16.83 \pm 0.87$ \\
\hline II & Negative control (Haloperidol 1 mg/kg) & $98.33 \pm 0.71^{* *, A}$ & $104.5 \pm 0.92^{* *, \mathrm{~A}}$ & $112.83 \pm 0.95^{* *, \mathrm{~A}}$ & $126.67 \pm 0.8^{* *, \mathrm{~A}}$ & $142.67 \pm 0.76^{* * A}$ & $163.17 \pm 0.91^{* *, A}$ \\
\hline III & METB (200 mg/kg) & $91.67 \pm 0.88^{* *, A, a}$ & $86.17 \pm 0.91^{* *, A, a}$ & $82.17 \pm 0.7^{* *, \mathrm{~A}, \mathrm{a}}$ & $76 \pm 0.86^{* *}, \mathrm{~A}, \mathrm{a}$ & $70.5 \pm 0.85^{* *, \mathrm{~A}, \mathrm{a}}$ & $65.5 \pm 0.96^{* *, \mathrm{~A}, \mathrm{a}}$ \\
\hline IV & METB (400 mg/kg) & $88.33 \pm 0.8^{* *, \mathrm{~B}, \mathrm{a}}$ & $84.83 \pm 0.83^{* *, \mathrm{~B}, \mathrm{a}}$ & $80.5 \pm 0.81^{* *, \mathrm{~B}, \mathrm{a}}$ & $74.67 \pm 0.71^{* *, B, a}$ & $69.83 \pm 0.98^{* *, \mathrm{~A}, \mathrm{a}}$ & $63.83 \pm 0.95^{* * \mathrm{~B}, \mathrm{a}}$ \\
\hline $\mathrm{V}$ & L-DOPA+ Carbidopa $(100+25$ mg/kg, p.o $)$ & $85.17 \pm 0.75^{* *, a}$ & $81.5 \pm 0.76^{* *, a}$ & $76.5 \pm 0.96^{* *, a}$ & $71.17 \pm 0.95^{* *, a}$ & $64.67 \pm 0.99^{+*, a}$ & $60 \pm 0.73^{* *, a}$ \\
\hline
\end{tabular}

Values were expressed as mean \pm SEM $(n=6)$. Statistical analysis was performed by using ANOVA followed by Dunnet's $t$-test by comparing with control, negative control and standard. Significant values are expressed as control group $\left({ }^{* *} p<0.01,{ }^{*} p<0.05\right)$, negative control $(\mathrm{a}=p<0.01, \mathrm{~b}=p<0.05)$ and standard $(\mathrm{A}=p<0.01, \mathrm{~B}=\mathrm{p}<0.05)$.

study. The other parameters, like food and water consumption, were also observed. All the animals were found to be safe even after 14days of observation. Hence the extract was found to be safe up to $2000 \mathrm{mg} / \mathrm{kg}$ bd. wt. The results of the AChE inhibitory activities of the METB as well as the positive control, Donepezil, are provided in Table 1.

In the present study, the methanolic extract of Terminalia bellerica fruits was investigated for its neuroprotective activity by using aluminium induced amnesia, haloperidol-induced catalepsy animal models and various behavioural parameters like passive avoidance time, transfer latency and basal activity score were evaluated. Aluminium is a ubiquitous metal that has been implicated in the aetiology of neurodegenerative disorders where it exacerbates oxidative brain damage, neuroinflammation and $\mathrm{A} \beta$ deposition. Aluminium is a prooxidant and indirectly results in the production of free radicals leading to oxidative damage and reduced levels of ROS, which indirectly affect acetyl cholinesterase enzyme activity. Aluminium causes disturbances in cholinergic neurotransmission and disrupts the cognitive behaviour of animals by increasing the stress levels. The parameters like transfer latency time and using elevated plus maze and passive avoidance time using Cook's pole climbing apparatus were depicted in Table 2 and 3. The elevations in AChE are either a direct result of the neurotoxic effect of metals or due to increased lipid peroxidation. ${ }^{11}$ Thus, reduced 
cholinergic activity due to the neurodegeneration in cortical regions is one of the consequences of ailment.

Characteristic neuroleptic mediators such as chlorpromazine, haloperidol and reserving persuade a cataleptic state in rodents, which is extensively, used as a model to trial the extrapyramidal side effects of the antipsychotic agents and the parameters like muscular rigidity and cataleptic scores were depicted in Table 4 and 5. Various neurotransmitters like dopamine, acetylcholine, serotonin, angiotensin, or uploads have been implicated in catalepsy induced by neuroleptic agents proof indicate the drugs which trigger the catalepsy rodents may reduce or aggravate extra pyramidal side effects in humans. ${ }^{12}$ In the present study, the extract protected mice from catalepsy induced by haloperidol as effectively as standard drug scopolamine.

The various phytochemicals identified in the methanolic extract of Terminalia bellerica fruits are phenolics like (phenolic acids and gallic acid), terpenoids like ( $\beta$ - amyrin and erythrodiol), flavonoids (quercetin, kaempferol), steroids ( $\beta$ - sitosterol, stigmasterol), carotenoids (lutein and zeaxanthin) and tocopherol ( $\alpha$ and $\beta$ tocopherol). It can be stated that the above said active constituents like phenolics, flavonoids, terpenoids and steroids had shown improvement in cognitive function by inhibiting AChE.

\section{CONCLUSION}

THE methanolic extract of Terminalia bellerica fruits was screened for its neuroprotective activity by using aluminium chloride-induced amnesia and haloperidol-induced catalepsy models. The animals have shown improvement in cognitive functions, which might be due to the presence of active constituents like phenols, flavonoids, terpenoids and steroids in the extract. In vitro cholinesterase enzyme content was analyzed by using Ellman's assay at different dose levels significantly inhibited the cholinesterase enzyme. The assay reports demonstrate a high AChE inhibitory activity of the extract. On the last day of chronic amnesic study, the brains of the animals were isolated and subjected for estimation of AChE and TBARS levels. Histopathological studies substantiated the memory retention activity of the extract. The results indicate that the underlying mechanism of learning and memory improvement may involve modulations of the cholinergic system and the reduction of oxidative stress. These findings thus provide evidence for the potential of TCE extract as a natural, alternative treatment for amnesia. Additional studies are required to be approved out to isolate individual phytochemical constituents of the extract and mechanism for its neuroprotective activity.

\section{ACKNOWLEDGEMENT}

The authors wish to thank Management, GRES and Principal Dr. C V S Subrahmanyam, Gokaraju Rangaraju College of Pharmacy, Bachupally, Hyderabad and Osmania University, Hyderabad for providing technical support and laboratory facility for the study.

\section{CONFLICT OF INTEREST}

All authors have no conflicts of interest to declare.

\section{ABBREVIATIONS USED}

METB: Methanolic extract of Terminalia bellerica; AD: Alzheimer's disease; AChE: Acetylcholinesterase; Al: Aluminium; APP: Amyloid precursor protein; CPCSEA: Committee for the Purpose of Control And Supervision of Experiments on Animals; IAEC: Institutional animal ethics committee; OECD: The Organisation for Economic Co-operation and Development.

\section{REFERENCES}

1. Parihar MS, Hemnani T. Alzheimer's disease pathogenesis and therapeutic interventions. J Clin Neurosci. 2004;11(5):456-67.

2. Nie K, Yu JC, FuY, Cheng HY, Chen FY, QuY. Age-related decrease in constructive activation of Akt/PKB in SAMP10 hippocampus. Biochem Biophys Res. 2009;378(1):103-7.

3. Kannan R, Sivaraman D, Muralidharan P, Deepakvenkataraman N. Neuroprotective effect of hydroalcoholic extract of areca catechu Linn on $\beta$-amyloid (25-35) induced cognitive dysfunction in mice. Int $\mathrm{J}$ Res in Ayur and Pharm. 2013;4(5):747-53.

4. Pemminati S, Nair V, Dorababu P, Gopalakrishna HN, Pai MR. Effect of aqueous fruit extract of Emblica officinalis on haloperidol induced catalepsy in albino mice. J Clin Diagn Res. 2009;3(4):1657-62.

5. Klemm WR. Evidence for a cholinergic role in haloperidol induced catalepsy. Psychopharmacol. 1985;85(2):139-42.

6. Khan AU, Gilani AH. Anti-secretory and analgesic activities of Terminalia belerica. Afr J Biotechnol. 2010;9(18):2717-9.

7. OECD. Guidance Document on Acute Oral Toxicity. Environmental Health and Safety Monograph Series on Testing and Assessment No 24. 2000.

8. Ellman G, Courtney $K$ andres V, Featherstone R. A new and rapid colorimetric determination of acetylcholinesterase activity. Biochem Pharmacol. $1961 ; 7(2): 88-95$

9. Ganga RM, Srilakshmi S. Anti-Amnesic effect of methanolic extract of Tageteserecta flower heads on Aluminium Induced Cognitive Impairment in Albino Mice. Res J Pharmacogn Phytochem. 2018;10(4):299-303.

10. Sanberg PR. Haloperidol induced catalepsy is mediated by postsynaptic dopamine receptors. Nature. 1980;284(5755):472-3.

11. Rani A, Neha SR, Kaur A. Protective effect of a calcium channel blocker "diltiazem" on aluminum chloride-induced dementia in mice. Naunyn-Schmiedeberg's Arc Pharmacol. 2015;388(11):1151-61.

12. Sushma NJ, Priyanka S, Rao JK. Neuroprotective role of dopamine levels in the rat brain. Neurotoxicology. 2011;2:347-53.

Article History: Submission Date : 19-03-2020; Revised Date : 29-04-2020; Acceptance Date : 30-05-2020

Cite this article: Reddy NVLSV, Raju GM, Goud RM, Shabnamkumari T. Neuroprotective Activity of Methanolic extract of Terminala bellerica Fruit against Aluminium Chloride and Haloperidol Induced Amnesia in Mice. J Young Pharm. 2020;12(2)Suppl:s87-s90. 